\title{
Efficacy of Certain Teaching Strategies on Reading Fluency Skills for Students of First Grad in Prep School
}

\author{
Sahar F. Ismael \\ Faculty of Education - Helwan University
}

\begin{abstract}
This research aimed at the development of reading fluency skills for Students of first grad prep School The research problem was mainly represented in weak reading fluency skills for students of first grad in prep School as well as negligence of modern teaching strategies. in order to find out a solution, the study passed through a set of steps. Most importantly were providing a list of reading fluency skills, suitable for Students of first grad in prep School, selecting three teaching strategies: modeling, collaborative learning and double reading, then, processing five prose texts within the first grad arabic language book using these three strategies one at a time. A manual for teachers was also provided and included performance steps, procedures, activities, means used and correction procedures per strategy. A research measured how far the three strategies were efficient for the development of reading fluency skills of the students. This was made by developing a note card for reading fluency skills as well as a measuring test and selecting three experimental groups, who are to be primarily subject to the test, within the students of first grad in prep School. After application of these three strategies to the groups, the test was subsequently post-applied. The research concluded a set of findings. A prominently important finding is that the three strategies were effective for the development of reading fluency skills for the for students of first grad in prep School. The results further showed that double reading strategy outperformed both modeling and collaborative strategies with regard to the development of the said skills.

Keywords: Reading Fluency; Teaching Strategies; Modeling Strategy; Collaborative Learning Strategy; Double Reading Strategy
\end{abstract}

Citation: Citation: Ismael, S., Efficacy of Certain Teaching Strategies on Reading Fluency Skills for Students of First Grad in Prep School, SVU-Journal of abstract 2020, 2 (1): pp.6 (retrieved from the SVU- International Journal Of Educational Sciences,2020, No 5).

Copyright: Publisher South Valley University. This is an open access article distributed under the terms of the creative common attribution license, which permits unrestricted use, distribution and reproduction in any medium provided the original author and source are created. 